\title{
Are Alcohol Related Social Problems More Likely To Occur in Wet Counties?
}

\author{
MICHAEL G. FULLINGTON \\ WILLIAM L. PRICE \\ RANDY L. ROEBUCK \\ Arkansas State University
}

During every general election for the past twenty years residents of at least one county in Arkansas have been asked whether they support the legal sale of intoxicating beverages. The study described below is designed to determine whether the 32 counties in Arkansas that presently allow the sale of alcoholic beverages have suffered from an increase in alcohol related social problems.

The legalization of liquor sales is a policy issue with significant social, political and emotional implications. Arkansas' community leaders and county residents have little evidence upon which to base objective and informed decisions about the legal sale of alcohol in their counties. Our goal is to help fill the void in documented data that currently exists and to assist policy makers in making more informed decisions about this important issue.

\section{What We Know About Alcohol Abuse}

The numerous social problems associated with the excessive consumption of alcoholic beverages have long been recognized: "Alcohol related arrests occur more frequently than arrests for any other type of crime" (Barlow, 1981, p. 306).

Child and spouse abuse are markedly higher among heavy alcohol users than among non-users (Hindman, 1977, p. 73). According to Kempe and Helfer (1972), alcohol is directly related to one out of three child abuse cases (see also Browning and Boatman, 1977). Roy (1977), concluded that over 80 percent of the wife beating cases examined in her study were alcohol related.

Alcohol is a factor in numerous violent acts. In Shelby County, Tennessee, it was found that $86 \%$ of apprehended murder suspects had been drinking immediately preceding the commission of the crime (Hollis, 1974). Noble (1976) suggests that alcohol use actually "triggers the aggressive factor" (p.9). Barlow (1981) concluded that "alcohol is most consistently and strongly linked with crimes, especially assaultive crimes such as homicides, aggravated assault, rape, and child beating" ( $p$. 309).

Perhaps the most devastating form of violence inflicted on society by alcohol abusers occurs when the intoxicated drinker gets behind the wheel of an automobile. Traffic accidents are the major cause of violent death in the United States and one half of all fatal accidents are alcohol related (NIAAA, 1981, p. 81 and NHTSA, 1978). These figures, unhappily, do not include the thousands of pedestrians killed or injured in alcohol related accidents (NHTSA, 1980/81). 
When the voters of Arkansas go to the polls to vote their counties wet or dry, they more than likely know that alcohol abuse can be deadly. But the legalization of the sale of alcohol within a county might not result in increased alcohol abuse on the part of the counties' residents. Even if alcohol consumption among county residents increases, this does not necessarily mean that the county will suffer from increased social problems (Barsby and Marshall, 1977).

The literature that comes closest to addressing this issue has focused on the association between lowered drinking ages and alcohol related arrests among the newly beveraged population. The results reported in some studies have been dramatic. Zylman (1974) found that "the number of 'alcohol involved' fatal crashes reported among drivers 18 to 20 years (increased by) $84 \%$ " after Michigan lowered its legal drinking age from 21 to 18 , alcohol related collisions increased by $174 \%$. Most of the literature agrees that as alcohol becomes more readily available to teenagers, consumption increases (Smart and Goodstadt, 1977). Furthermore, it is fairly clear that this increased consumption translates into increased accidents among the inebriated youth (see also Naor and Nashold, 1975 and Whithead, 1977).

Still, policy makers do not know if the general population will respond as the less mature adolescents years of age are less likely to change their drinking patterns significantly even when alcohol is more readily available. We would not expect the problems associated with alcohol abuse to rise if levels of alcohol consumption do not respond to the availability of alcohol. Our methodology does not allow us to address whether alcohol consumption is higher in Arkansas' wet counties (counties in which alcoholic beverages are sold legally by licensed retail vendors) than in the dry counties (counties in which alcoholic beverages may not be purchased outside of private clubs). But, we will address the important issue of whether alcohol related problems are greater in wet counties than in counties in which the retail sales of alcohol outside of private clubs is prohibited.

\section{Scope of the Study}

The state of Arkansas is divided into 75 counties. According to the Alcoholic Beverage Control Division for the state and verified by telephone interviews of the county clerks in each county, 32 counties are classified as "wet" and 43 counties are classified as "dry". Though the question of whether to change from wet to dry or dry to wet is often placed on the ballots in these counties, the voters have rarely chosen to change the status quo. In fact, with the exception of Baxter and Bradley counties, every dry county in the state has been dry for at least 25 years and every wet county has been wet for at least the same period of time.

Two counties, Drew and Logan, are legally wet, but many of the townships within those counties have selected to abstain from the legal sale of alcoholic beverages. Therefore, Drew and Logan counties were removed from the analysis because they could not clearly be classified as wet or dry. Bradley was maintained because it has been wet since the 1960s and Baxter was classified as dry because it was dry from 1945 to 1981 and then turned wet in 1981. All data analyzed are applicable to 1980 . As a result, our analysis centers on 30 wet and 43 dry counties for a total of 73 cases.

\section{Findings}

The specific social problems we chose to examine are: violent crimes, property crimes, offenses against family and children, and arrests for driving under the 


\section{Fullington, Price, and Roebuck}

influence of alcohol (data are from the U.S. Department of Commerce, 1980). As noted above, these are often defined as alcohol related social problems and may increase if alcohol abuse rises as alcohol becomes more available in a county (Barlow, 1981; Haskell and Yablonsky, 1978).

We first compared the levels of the four social problems experienced by wet and dry counties in Arkansas. The results reported in Table 1 indi cate that wet counties in Arkansas experience higher levels, than dry counties, of every social problem examined. In fact, the differences are rather dramatic.

Compared with dry counties, the average level of violent crimes per capita is three times as high in the wet counties of Arkansas. The average number of property crimes is twice as high and arrests for driving while intoxicated one and one half times as high in the wet than in the dry counties of the state. Sadly, the number of reported cases of child abuse per capita are twice as likely to occur in the wet counties of Arkansas. The Student's $t$ and probability levels were computed to test whether or not the difference between the mean level of each social problem is significant between the wet and dry counties of the state (Nie, et al., 1975, p. 268).

Table 1. The Number of Social Problems Per Capita in the Wet and Dry Counties of Arkansas

\begin{tabular}{|c|c|c|}
\hline Viole & Property & $\begin{array}{l}\text { Driving } \\
\text { While }\end{array}$ \\
\hline Crimes & Crimes & Intoxicated \\
\hline
\end{tabular}

Dry Counties

$\begin{array}{lllll}\text { Mean } & .9 & 14.9 & 7.2 & \\ \text { Stand. Dev } & .1 & 8.0 & 4.0 & 0\end{array}$

Wet Counties

$\begin{array}{lllll}\text { Mean } & 2.9 & 29.9 & 11.2 & \\ \text { Stand.Dev } & .2 & 16.0 & 8.0 & .1 \\ & 5.33 & 5.22 & 2.79 & 1.56\end{array}$

1 tail

Prob. (less than)

.01

.01

.01

.06

+ all figures reported are per 1000 county residents

We asked ourselves what would happen to the results if we eliminated the effects of those variables often considered important indicators of crime in America. The variables considered important in this analysis were per capita income, total population size, percentage of the county living in urban areas, percentage of the population classified as minority, per centage of population with a high school degree and the counties' unemployment rates. Each of these factors could logically influence the degree to which the counties experience the social problems considered. For sake of clarity, we will refer to each of these social, economic and demographic factors as "controlled variables." 
To determined whether wet counties are still more likely than dry counties to experience the four noted social problems after the effects of all the social, economic and demographic variables are removed (controlled), we used a partial correlation technique. Partial correlation "provides the researcher with a single measure of association describing the relationship between two variables while adjusting for the effects of one or more additional variables" (Nie, et al., 1975, p. 302). In this way we were able to examine the correlation coefficients remaining between the wetdry variable (treated as a dummy variable-wet/non-wet) and each social problem after accounting for the effects of all other variables.

Table 2 indicates that after the effects of the controlled variables are considered there is a significant relationship between a county being wet or dry and all but one of the social problem variables. The percentage of violent crimes, property crimes, and cases of driving under the influence, all have strong and significant relationships with the wet/dry dummy variable after the effects of the six "controlled variables" are removed. On the other hand, the number of occurrences of family related violence is not strongly related to a county being wet or dry once the six social, economic and demographic variables are considered.

\section{Conclusion}

The goal of this analysis was to better understand whether alcohol related social problems are more likely to occur in Arkansas counties in which the sale of liquor is legal. We found strong evidence that three of the four social problems examined (violent crimes, property crimes and driving while intoxicated) occur more frequently in the wet, than in the dry, counties of the state. Even when the effects of other factors like population size, urbanization, income, racial composition, and education are removed, we still found evidence that wet counties are more likely to suffer from these social problems.

This topic is ripe for research. Among the numerous questions that remain to be examined in future analyses are: 1) Do counties in Arkansas that are dry but bordered by wet counties experience higher levels of alcohol related social problems than their dry counterparts without legal alcohol sales nearby; and 2) What other factors should be considered that might either weaken or strengthen the associations reported above?

Table 2. Partial Correlation Coefficients Between Wet/Dry Dummy Variable and Each Social Problem

\begin{tabular}{lll}
\hline & $\begin{array}{l}\text { Zero Order } \\
\text { Correlation }\end{array}$ & $\begin{array}{l}\text { 6th Order } \\
\text { Correlation }\end{array}$ \\
\hline Violent Crimes & .53 & .33 \\
& signif. $<.01$ & signif. $<.05$ \\
Property Crimes & .53 & .43 \\
& signif. $<.01$ & signif. $<.01$ \\
Offenses Against & .18 & .09 \\
Family \& Children & signif. $<.06$ & signif. $>.10$ \\
Driving While & .31 & .30 \\
Intoxicated & signif. $<.01$ & signif. $<.05$
\end{tabular}

these figures are simple product moment correlations

these figures are the correlation coefficients remaining between the wevdry dummy variable and the noted social problem after the effects of the six "controlled variables" have been considered. 
We have examined a question that has been asked during every Arkansas general election for the past twenty years. In addition, we have attempted to provide some data that are directly applicable to Arkansas. To date, policy makers have been forced to rely on evidence from areas outside Arkansas' borders (particularly Oklahoma and Texas). Perhaps, with continued research in the area, we will be better able to address this important topic in a more informed manner.

\section{References}

Arkansas Crime Information Center, (1981). Crime in Arkansas 1980. Little Rock: Author.

Barlow, H.D., (1981). Introduction to Criminology, 2nd. ed. Boston: Little Brown.

Barsby, S.L. \& Marshall, B.L., (1977). "Short-Term Consumption Effects of a Lower Minimum AlcoholPurchasing Age." Journal of Studies on Alcohol, 38.

Browning, D. and Boatman, B., (1977). "Incest: Children at Risk" American Journal of Psychiatry, 134.

California Department of Public Health, (1960). Criminal Offenses and Drinking Involvement: A Preliminary Analysis. Sacramento: Author.

Haskell, M.R. \& Yablonsky, (1978). L. Criminology: Crime and Personality 2nd ed. Chicago: Rand McNally.

Hindman, M., (1977). Child Abuse and Neglect: The Alcohol Connection. Alcohol Health and Research World, 1 .

Hollis, W.S., (1974). "On the Etiology of Criminal Homicides-the Alcohol Factor." Journal of Police Science and Administration, 2.

Kempe, C.H. and Helfer, R.E., (1972). Helping the Battered Child and His Family. New York: Lippincott.

Naor, E.M. and Nashold, R.D., (1975). "Teenage Driver Fatalities Following Reduction in the Legal Drinking Age." Journal of Safety Research, 7.

National Institute on Alcohol Abuse and Alcoholism, (1981). Fourth Special Report to the U.S. Congress on Alcohol and Health from the Secretary of Health and Human Services, January 1981. Washington, D.C.: G.P.O.

National Highway Traffic Safety Administration, (1978). Alcohol/Highway Safety Review, Washington, D.C.: G.P.O.

National Highway Traffic Safety Administration, (1981). Alcohol/Highway Safety Review. Washington, D.C.: G.P.O.

Noble, E.P. Speech Before Scientific Symposium on Advances in Knowledge About Substance Abuse (October 21, 1976) reported in John W. Harrison, (1978). Alcoholism and Criminal Homicide: An Overview. Alcohol Health and Research Worid.

Pedhazur, E.J., (1982). Multiple Regression in Behavioral Research Explanation and Prediction, 2nd ed. New York: Holt, Rinehart, Winston.

Roy, M., (1977). Battered Women: A Psychosociological Study of Domestic Violence. New York: Van Nostrand Reinhold.

Smart, R.G. and Finley, D., (1975). Increases in Youthful Admissions to Alcoholism Treatment in Ontario. Drug and Alcohol Dependence, 1.

Smart, R.G. and Goodstadt, M.S., (1977). "Effects of Reducing the Legal Alcohol Purchasing Age on Drinking and Drinking Problems a Review of Empirical Studies." Journal of Studies on Alcohol, 38.

Tindlenburg, J., (1973). Drugs and Crime, in National Commission on Marijuana and Drug Abuse. Patterns and Consequences of Drug Use. Washington, D.C.: G.P.O. 
U.S. Congress, House Committee on Education and Labor, Methods of Prevention and Treatment Related to Domestic Violence. Hearings Before the Subcommittee on Special Education on H.R. 7927 and H.R. 8948, Congressional Record 124.

U.S. Department of Commerce, Bureau of the Census, (1980). Census of Population: 1980. Washington, D.C.: G.P.O.

Whitehead, P.C., et al., (1977). "Collision Behavior of Young Drivers: Impact of the Change in the Age of Majority." Journal of Studies on Alcohol, 36.

Zylman, R., (1974). "Fatal Crashes Among Michigan Youth Following Reduction of Legal Drinking Age." Quarterly Journal of Studies on Alcohol, 35. 